\title{
GEDUNG PARKIR DI SEMINYAK KUTA-BADUNG
}

\author{
I Nyoman Gede Suaryadinata \\ Program Studi Arsitektur Fakultas Teknik Universitas Dwijendra \\ (desuaryadinata@gmail.com) \\ Putu Gde Ery Suardana \\ Program Studi Arsitektur Fakultas Teknik Universitas Dwijendra \\ (erisuardana@undwi.ac.id)
}

\begin{abstract}
Abstrak
Kunjungan wisatawan ke Bali tiap tahunnya semakin meningkat, hal ini secara langsung berdampak kepada kepadatan lalu lintas. Khususnya kawasan Seminyak yang merupakan primadona pusat hiburan dan wisata di Bali Selatan. Banyaknya para wisatawan yang berkunjung ke kawasan Seminyak, berdampak pada meningkatnya jumlah kendaraan yang melintas di kawasan tersebut. Permasalahan yang terjadi adalah tidak seimbangnya antara jumlah kendaraan yang parkir dengan lahan parkir yang tersedia, hal ini menyebabkan terjadinya kemacetan di kawasan tersebut karena banyak adanya pelanggaran lalu lintas. Untuk mengatasi permasalahan tersebut, maka perlu diadakannya sebuah wadah guna menampung kendaraan-kendaraan yang akan parkir. Wadah tersebut dapat berupa sebuah Gedung Parkir yang dimana nantinya diharapkan dapat mengurangi tingkat kemacetan yang diakibatkan oleh pelanggaran lalu lintas kendaraan yang parkir disembarang jalan.

Penelitian menggunakan pendekatan induktif untuk membangun konsep-konsep perancangan dan perencanaan. Konsep tersebut dirumuskan dari beberapa unsur/unit informasi di antaranya: hasil observasi lapangan, wawancara dengan ahli/dinas terkait, studi literatur, studi banding dan studi standar-standar arsitektur serta studi peraturan daerah.

Dalam perencanaan dan perancangan Gedung Parkir di Seminyak Kuta-Badung ini menerapkan tema Arsitektur High Tech, yang dimana penerapannya lebih menonjolakan nilai dasar fungsional dari bangunan tersebut dengan cara mengekspos bentuk struktur dan peralatan ME didalamnya. Konsep dasar dari bangunan ini juga mengedepankan nilai fungsional didalamnya yaitu Aman dan Efektif. Seperti maknanya kata "aman" disini memiliki arti yaitu dapat memberikan keadaan bebas dari bahaya. Istilah ini bisa digunakan dengan hubungan kepada kejahatan, segala bentuk kecelakaan, dan lain-lain. Sedangkan kata "efektif" memiliki arti dapat menciptakan sirkulasi dan ruang yang ada harus ditata dengan baik dan teratur agar dapat dimanfaatkan secara maksimal.
\end{abstract}

Kata Kunci: Gedung parkir, kendaraan, Seminyak

\begin{abstract}
Tourist visits to Bali increase every year, this directly impacts traffic density. Especially the Seminyak area which is the center of entertainment and tourism in South Bali. The number of tourists visiting the Seminyak area had an impact on the increasing number of vehicles passing in the area. The problem that occurs is the imbalance between the number of parking vehicles and available parking, this causes congestion in the area due to many traffic violations. To overcome these problems, it is necessary to hold a container to accommodate vehicles that will park. The container can be in the form of a Parking Building which is expected to reduce the level of congestion caused by traffic violations of vehicles parked on the road.

Research uses an inductive approach to construct design and planning concepts. The concept was formulated from several elements / units of information including: results of field observations, interviews with experts / related agencies, literature studies, comparative studies and studies of architectural standards as well as regional regulation studies.
\end{abstract}


In planning and designing the Parking Building in Seminyak, Kuta-Badung applies the High Tech Architecture theme, in which the application is more prominent in the functional basic value of the building by exposing the structure and ME equipment in it. The basic concept of this building also puts forward the functional value in it, namely Safe and Effective. As the meaning of the word "safe" here means that it can provide a state free from danger. This term can be used with regard to crime, all forms of accidents, and others. Whereas the word "effective" means that it can create circulation and the existing space must be arranged properly and regularly so that it can be utilized optimally.

Keywords : Parking building, transportation, Seminyak

\section{1. PENDAHULUAN}

\subsection{Latar Belakang}

Bali merupakan tujuan wisata bagi wisatawan domestik maupun mancanegara, dan kawasan Seminyak merupakan salah satu yang menjadi tujuan favoritnya. Banyak terdapat objek wisata dan tempat hiburan di kawasan Seminyak, sehingga kawasan ini padat lalu lintas. Meningkatnya jumlah kendaraan di kawasan Seminyak tidak sebanding dengan jumlah lahan parkir yang tersedia. Badan Pusat Statistik (BPS) pada tahun 2016 mencatat jumlah kendaraan yang melintas dan parkir dikawasan tersebut sebanyak + 47.800 unit/hari, sedangkan lahan parkir yang tersedia hanya seluas $20.500 \mathrm{~m} 2$. Hal ini dirasa sangat kurang jika dihitung per unit kendaraan membutuhkan satuan ruang parkir $(\mathrm{SRP})+12.5 \mathrm{~m} 2$.

Pemerintah sudah berupaya mengatasi masalah ini dengan membangun Central Parkir di Jalan Raya Kuta dan menyediakan bus mini komotra sebagai akomodasi, namun cara ini belum efektif dan efisien. Sehingga diperlukan sebuah wadah yang dapat menampung kendaraan di kawasan Seminyak ini (Gedung Parkir). Dengan dibangunnya sebuah wadah berupa Gedung Parkir di Seminyak Kuta-Badung ini, diharapkan nantinya dapat mengurangi tingkat kemacetan dan juga pelanggaran-pelanggaran lalu lintas yang terjadi.

\subsection{Rumusan Masalah}

Dari latar belakang tersebut, dapat dirumuskan beberapa pokok permasalahan sebagai berikut:

1. Mengapa perlu diadakannya Gedung Parkir di Seminyak, Kuta-Badung?

2. Bagaimanakah program perancangan bangunan yang tepat untuk diterapkan pada Gedung Parkir di Seminyak, Kuta-Badung?

3. Bagaimanakah konsep perancangan bangunan yang tepat dan optimal untuk diterapkan pada Gedung Parkir di Seminyak, Kuta-Badung?

\section{METODE}

2.1 Tahap Pengumpulan Data

Dalam tahap pengumpulan data, data yang diperoleh akan dibedakan menjadi 2 (dua) macam berdasarkan sumber datanya, yaitu sebagai berikut:

Data Primer

Merupakan suatu metode pengumpulan data dengan cara melakukan penelitian secara langsung pada sumbernya. Dimana data primer dapat dikumpulkan dengan cara:

1. Observasi

Mengadakan observasi atau studi banding terhadap proyek sejenis dengan mengadakan pengamatan langsung untuk mendapatkan informasi.

\section{Wawancara}


Mengadakan wawancara dengan para ahli atau pihak-pihak terkait untuk memperoleh data-data yang digunakan untuk pendekatan dan penganalisisan data.

Data Sekunder

Merupakan data-data literatur yang bersifat teoritis (baik yang ditulis oleh para ahli ataupun pendapat dari berbagai narasumber yang berkompeten) yang memperkuat permasalahan yang diangkat, literatur diperoleh dari berbagai buku bacaan maupun browsing data melalui internet. Data sekunder yang dapat diperoleh dari:

1. Studi Kepustakaan

Merupakan teknik pengumpulan data melalui literatur-literatur, buku-buku, majalah ataupun artikel yang berkaitan dengan Gedung Parkir.

2. Studi Instansional

Studi instansional dilakukan dengan mencari data terkait dengan peraturan yang diperlukan dalam perencanaan dan perancangan. Data tersebut berupa peraturanperaturan yang dikeluarkan oleh pemerintah (perda), RTRW dan RDTR wilayah lokasi yang akan dibangun Gedung Parkir, serta Data Fisik dan Non Fisik Daerah tujuan proyek.

3. Browsing Internet

Pengumpulan data mengenai proyek sejenis dengan cara pencarian melalui media internet, ataupun website untuk mendapatkan gambaran mengenai kegiatan serta fasilitas yang digunakan berhubungan dengan Gedung Parkir.

2.2 Tahap Analisis Data

Teknik analisis data dilakukan dengan dua cara yaitu:

a. Kualitatif

Yaitu menganalisis data dengan cara mendeskripsikan data membuat diagramatik seperti menyimpulkan studi banding.

b. Kuantitatif

Yaitu menganalisis data dengan cara perhitungan matematis seperti perhitungan jumlah pengunjung, volume kendaraan, dan pengelola dalam perencanaan dan perancangan Gedung Parkir di Seminyak, Kuta-Badung.

2.3 Tahap Penyimpulan Data

Metode tahap penyimpulan data yang digunakan adalah metode Deduktif, yaitu metode pemikiran yang bertitik tolak dari hal-hal umum yang mengarah pada kesimpulan yang sifatnya khusus.

\section{HASIL DAN PEMBAHASAN}

1. Tema Rancangan dan Konsep Dasar Rancangan

Tema rancangan dibangun setelah menimbang secara mendalam beberapa pendekatan tema (Miarsono, 1992): pendekatan dari segi fungsi, pendekatan dari segi proses kegiatan, pendekatan latar belakang budaya, maka tema rancangan sebagai tema empiris yang lahir adalah Arsitektur High Tech.

Sementara itu, dari unit-unit informasi yang dikaji mendalam, seperti : pengertian, tujuan, sasaran dan fungsi wadah Gedung Parkir di Seminyak Kuta-Badung dapat dirumuskan tema empiris konsep dasar rancangan : (i) aman, (ii) efektif.

\section{Program Fungsional}

Unit-unit informasi yang dikaji mendalam terhadap identifikasi pada pelaku kegiatan/ civitas seperti ; pengunjung, pengelola maupun servis serta aneka kegiatan/aktivitas dan fasilitas penunjang kegiatan, menghasilkan tema empiris berupa program fungsional (didalamnya terdapat jenis kebutuhan ruang dan kapasitas ruang). Kebutuhan ruang-ruang untuk utama terdiri dari ; area parkir, cashier, ruang tunggu, 
public toilet. Sementara ruang-ruang pengelola terdiri dari : ruang direktur, ruang manager, ruang staff, gudang, kantin, toilet. Dan untuk ruang-ruang penunjang terdiri dari : tempat suci, ruang security, smoking area, kantin.

\section{Program Performansi}

Berdasarkan atas jenis kebutuhan ruang seperti pada program fungsional serta dikaitkan dengan kesamaan kegiatan dan karakteristik kegiatan maka muncul tema empiris program performasi yang didalamnya terdapat pengelompokkan ruang, tuntutan ruang dan sifat ruang, Kelompok ruang tersebut antara lain : (i) gedung parkir, (ii) ruang servis, (iii) ruang pengelola, (iv) ruang penunjang.

4. Program Arsitektural

Terjemahan secara efektif dari pengelompokkan ruang dan persyaratan ruang memunculkan tema empiris program arsitektural, didalamnya terdapat besaran ruang, hubungan ruang, sirkulasi ruang dan organisasi ruang. Hasil studi atas besaran luas lantai dasar adalah sebesar $1677.07 \mathrm{~m} 2$. Luasan ini merupakan luas koefisien dasar bangunan (KDB) site sebagai dasar penentuan luar site yang dibutuhkan. Koefisien Ddasar Bangunan yang digunakan sebesar 50\%, maka kebutuhan lahan adalah sebesar 100/50 X $1677.07 \mathrm{~m} 2$. Perkalian ini menghasilkan kebutuhan lahan sebesar: $3354.14 \mathrm{~m} 2$ atau seluas 34 Are.

Hubungan ruang dibangun berdasarkan atas sifat dan tuntutan masing-masing kelompok ruang seperti di atas, memunculkan hubungan ruang mikro dan hubungan ruang makro. pada akhir kan keseluruhan hubungan ruang ini menghasilkan organisasi ruang berikut sirkulasinya, seperti pada Gambar 1 di bawah.

\section{Program Tapak}

Lokasi Gedung Parkir di Seminyak Kuta-Badung terletak di Jalan Oberoi, dengan luasan tapak sebesar $\pm 3770 \mathrm{~m}^{2}$ (Gambar 2)

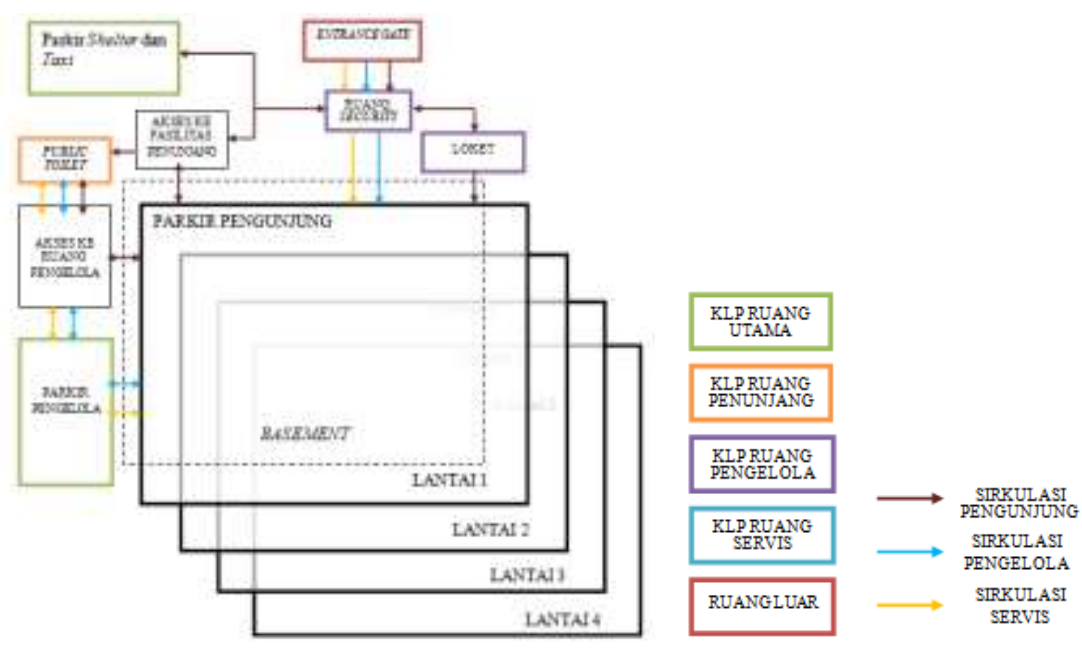

Gambar 1. Hubungan Ruang dan Sirkulasi Ruang Sumber : Hasil Analisis
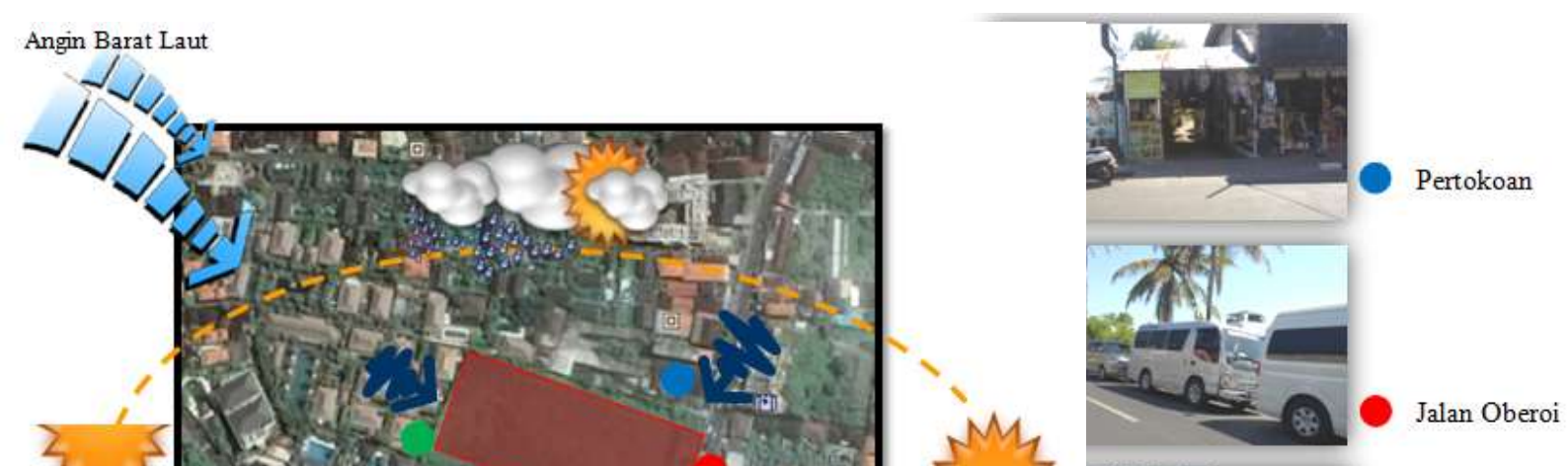
Gambar 2. Karakteristik Tapak

Sumber : Hasil Analisis

\section{Konsep Entrance Tapak}

\section{MAIN ENTRANCE}

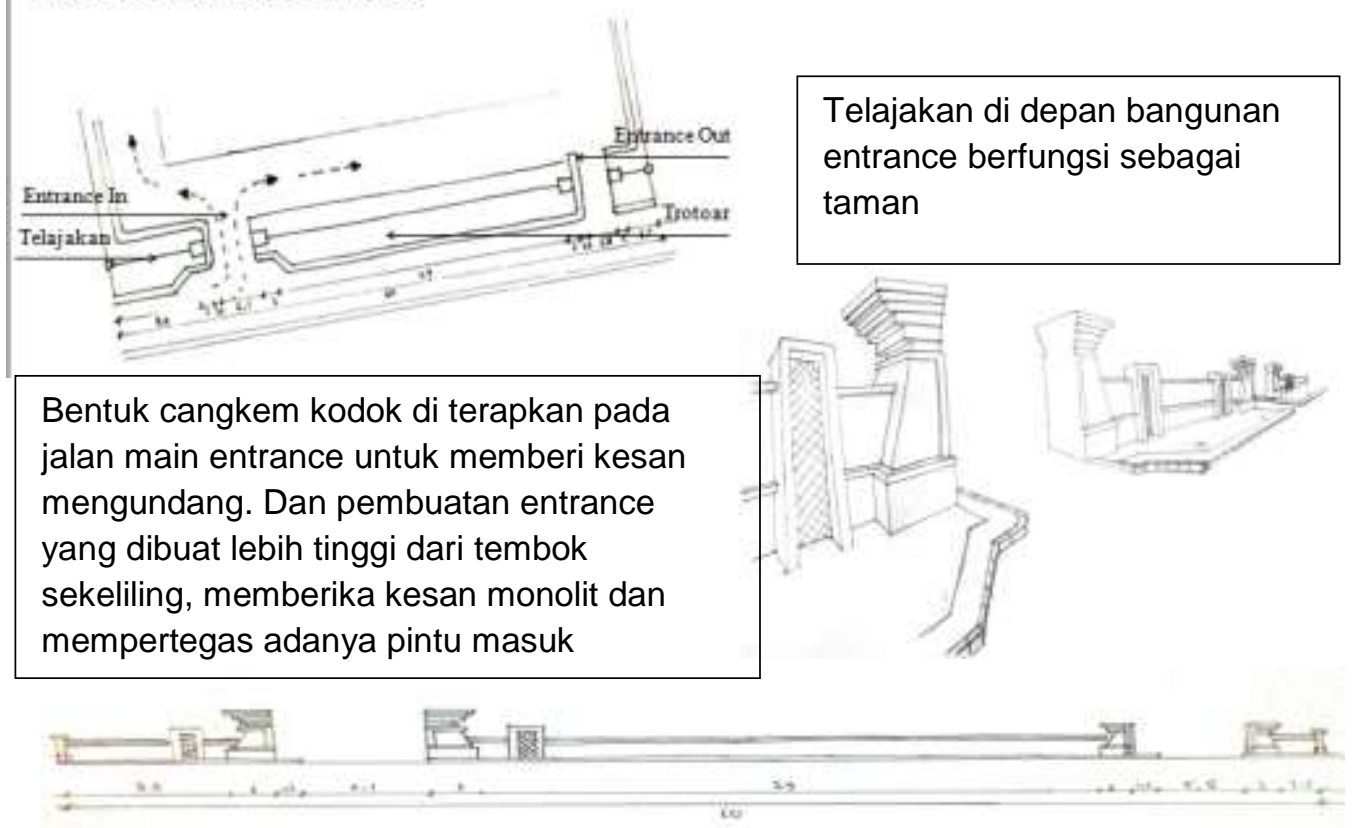

Gambar 3. Konsep Entrance Tapak

Sumber : Hasil Analisis 


\section{Jurnal AMALA}

Volume 9, No. 1 | Februari 2021

7. Konsep Sirkulasi Bangunan

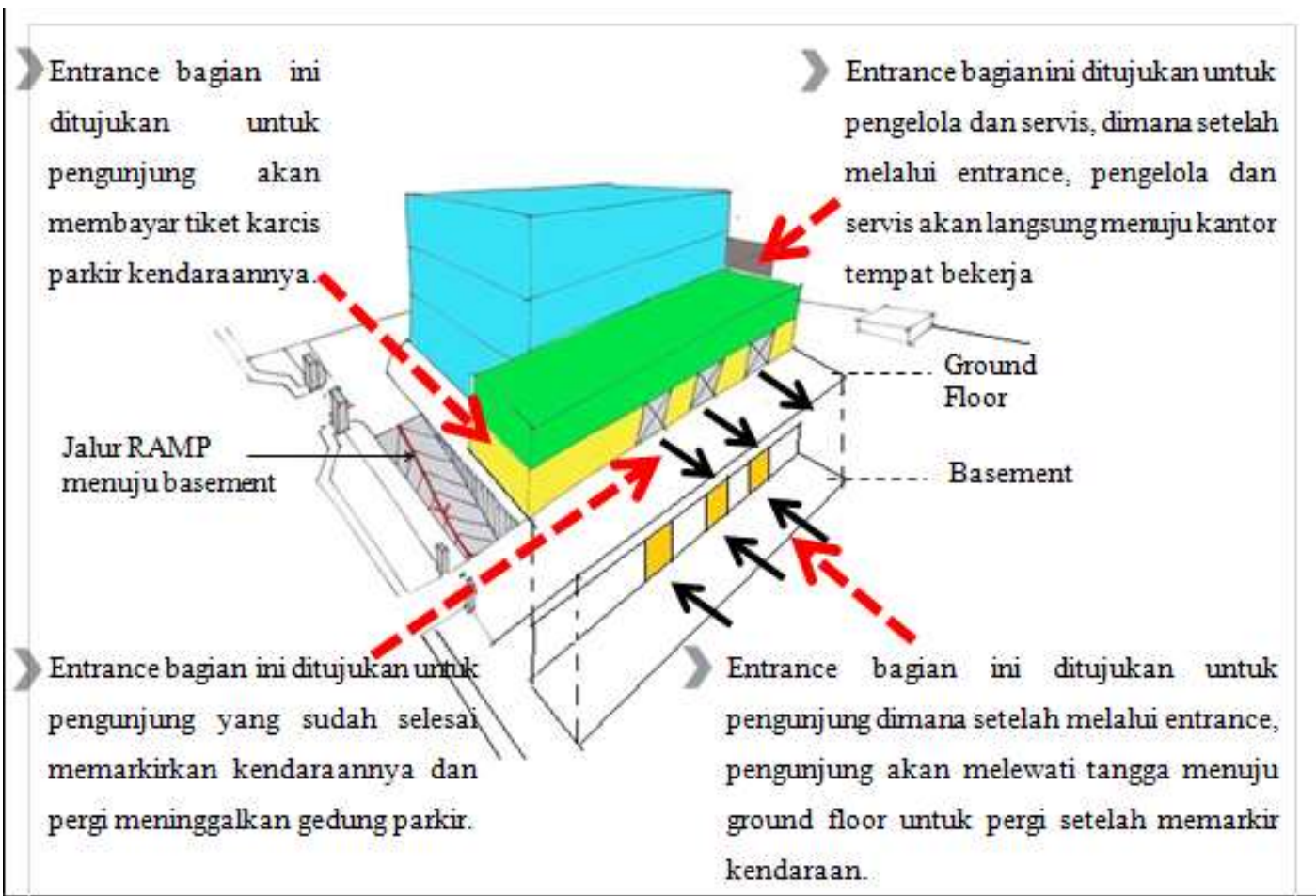

Gambar 4. Konsep Sirkulasi Bangunan Sumber : Hasil Analisis

\section{PENUTUP}

\section{Simpulan}

Dari uraian pada pembahasan di muka, dapat dirumuskan beberapa hal terkait dengan Gedung Parkir di Seminyak Kuta-Badung, sebagai berikut.

1. Konsep perancangan bangunan sebagai hasil reduksi eidetis atas tema-tema empiris di atas, antara lain :

a. konsep bentuk masssa ; bentuk dasar persegi

b. konsep pola massa : monolit.

c. konsep orientasi massa : menghadap ke jalan utama.

d. konsep tampilan bangunan : implementasi atas tri angga, kepala, badan dan atap/kepala.

2. Fasilitas yang ada pada Gedung Parkir di Seminyak Kuta-Badung terdiri dari :
a. Fasilitas utama: area parkir.
b. Fasilitas pengelola: ruang direktur, ruang manager, ruang staff, toilet.
c. Fasilitas penunjang: cashier, pos satpam, kantin, smoking area, tempat suci.

3. Bentuk penampilan arsitektur untuk Gedung Parkir di Seminyak Kuta-Badung:
a. disesuaikan dengan tema rancangan Arsitektur High Tech (sistem struktur modern dengan material dominan baja, kaca, aluminium).
b. mengimplementasi konsep tri angga (kepala badan dan kaki) pada facade bangunan,
c. menerapkan utilitas yang modern dan secara automatic. 


\section{Saran}

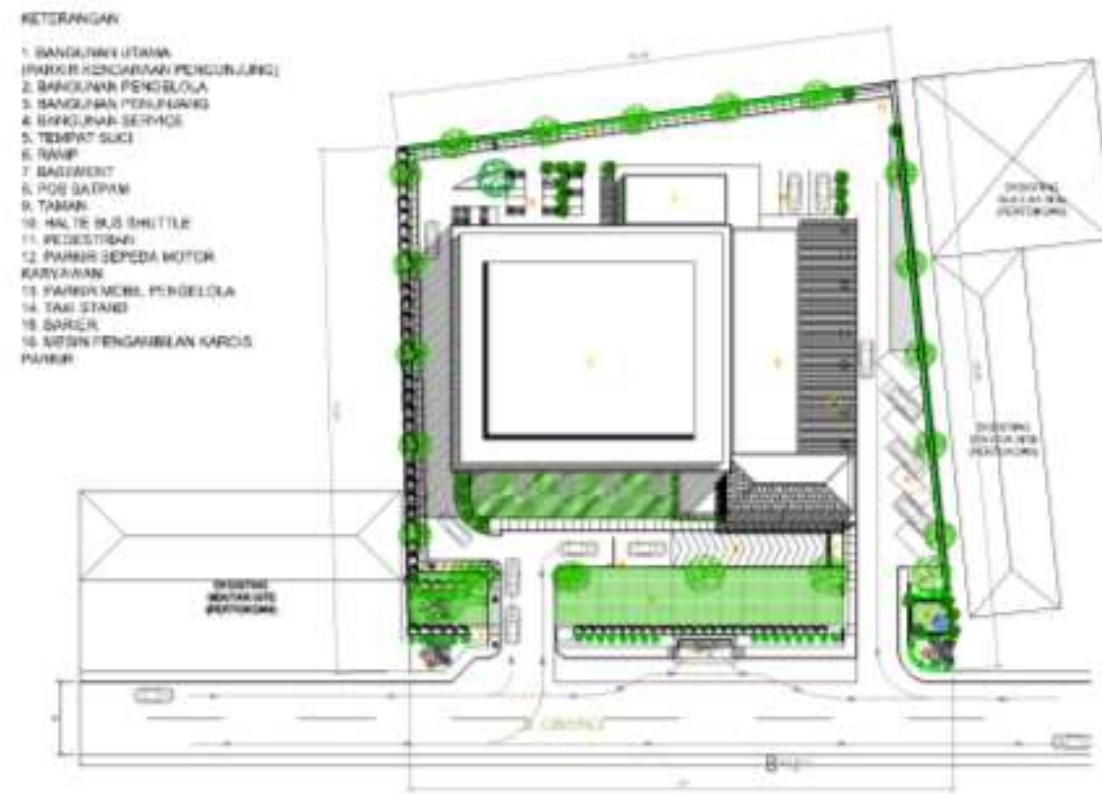

Gambar 5. Site Plan

Sumber : Hasil Transformasi Konsep

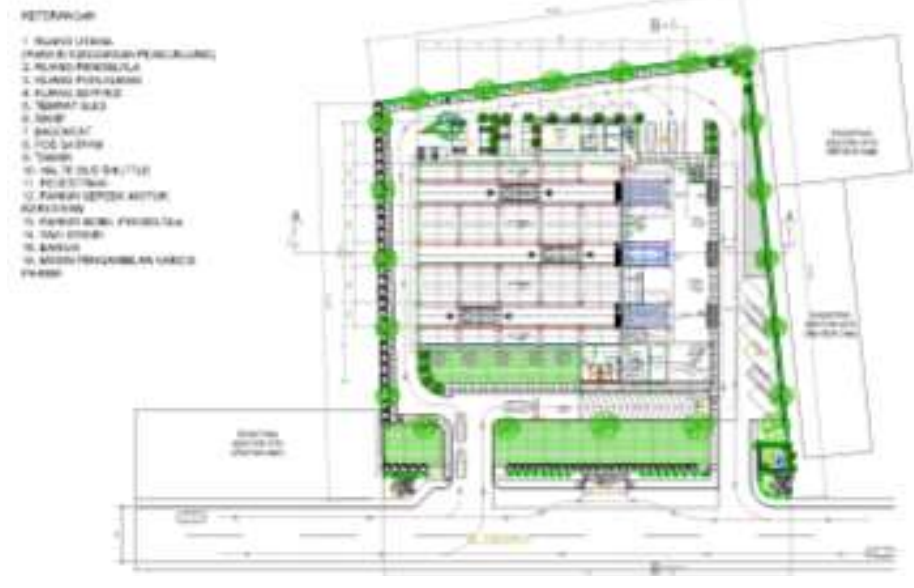

Gambar 6. Layout Plan

Sumber : Hasil Transformasi

Konsep

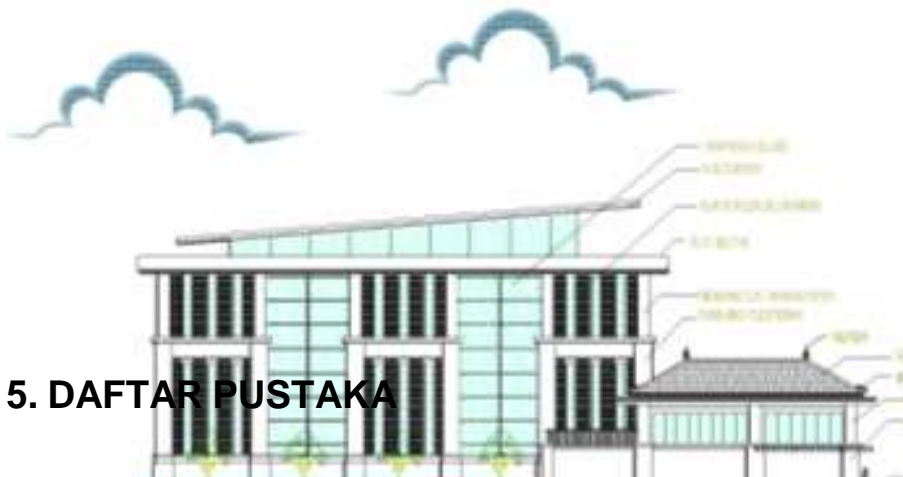

Gambar 7. Tampak Plan

Sumber : Hasil Transformasi

Badan Pusat Statistik Provinsi Bali. 2016. Bali dalam Angka 2016. 
Direktorat Jenderal Perhubungan Darat Nomor: 272/HK.105/DRJD/98. Pedoman Teknis Penyelenggaraan Fasilitas Parkir. Jakarta: Direktur Jendral Perhubungan Darat.

Miarsono, Ir. Harry. 1992. Perkembangan Arsitektur High-Tech. Majalah Konstruksi.

Neufert, E. and Neufert, P. 2000. Architects' Data. Oxford: Blackwell Science Ltd.

Oppenlander, Joseph C. 1976. Manual of Traffic Engineering Studies, Institute of transportation engineers, Virginia.

Peraturan Menteri Pekerjaan Umum Nomor: 29/PRT/M/2006. Pedoman Persyaratan Teknis Bangunan Gedung. Bandung: Balitbang, Departemen Pekerjaan Umum.

Utomo, Eko. 2012. Struktur Gedung Parkir. (http://ekoutomo84.blogspot.co.id/2012/07/struktur-gedung-parkir.html) diakses 3 Maret 2018.

Warpani, Suwardjoko. 1988. Rekayasa Lalu Lintas. Jakarta: Bharata.

Wikipedia. 2018. Bangunan. (http://id.wikipedia.org/wiki/Bangunan) diakses 20 Februari 2018. 